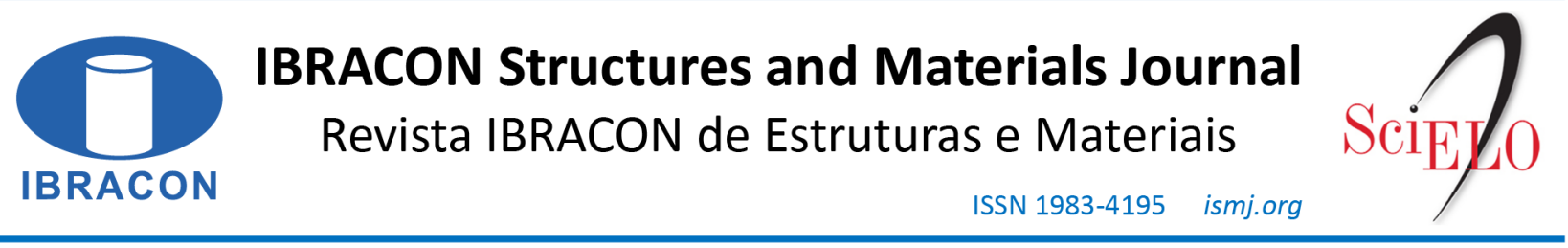

ORIGINAL ARTICLE

\title{
Human comfort assessment of buildings subjected to nondeterministic wind dynamic loadings
}

\section{Avaliação do conforto humano de edifícios submetidos a carregamentos dinâmicos não determinísticos de vento}

\author{
Alan Barile ${ }^{\mathrm{a}}$ \\ Leonardo de Souza Bastos ${ }^{\mathrm{a}}$ (1) \\ José Guilherme Santos da Silva ${ }^{a}$
}

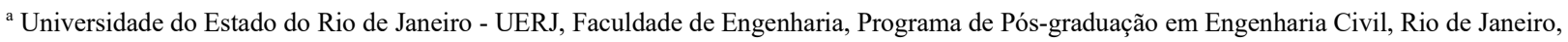
RJ, Brasil
\end{abstract}

Received 04 April 2019

Accepted 13 January 2020

\begin{abstract}
A reliable human comfort assessment depends on the correct description of the wind dynamic loads when compared with studies of natural wind. Thus, in this research work an analysis methodology was developed aiming to generate nondeterministic dynamic wind loadings, based on a power spectral density function and coherence function. This way, aiming to test the developed analysis methodology, a forced vibration dynamic analysis was carried out, based on a three-dimensional finite element model developed to represent a real and existing thirty-storey reinforced concrete building, with total height of $90 \mathrm{~m}$, store height equal to $3 \mathrm{~m}$ and rectangular dimensions of $21.50 \mathrm{~m}$ by $17.30 \mathrm{~m}$. The dynamic structural response of the investigated building was evaluated, the accelerations at the top of the structure were calculated and the human comfort was verified. The results obtained along this research work indicate that the peak accelerations calculated for periods of recurrence equal to 10 years and 1 year, respectively, overpass the recommended limits proposed by the NBR 6123 and ISO 10137.
\end{abstract}

Keywords: buildings, wind loads, human comfort, structural dynamics.

\begin{abstract}
Resumo: Uma avaliação confiável do conforto humano depende da descrição correta das cargas dinâmicas de vento, quando comparadas com estudos acerca do vento natural. Assim sendo, neste trabalho de pesquisa foi desenvolvida uma metodologia de análise com o objetivo de gerar cargas dinâmicas não determinísticas de vento, com base no emprego de uma função de densidade espectral de potência e função de coerência. Deste modo, objetivando testar a metodologia de análise proposta, foi realizada uma análise dinâmica de vibração forçada, com base no uso de um modelo tridimensional de elementos finitos desenvolvido para representar um edifício de concreto armado com trinta pavimentos, real e existente, com altura total de $90 \mathrm{~m}$, pé-direito de $3 \mathrm{~m}$ e dimensões em planta de 21,50 m x 17,30 $\mathrm{m}$. A resposta estrutural dinâmica do edifício investigado foi avaliada, as acelerações no topo da estrutura foram calculadas, e o conforto humano foi verificado. Os resultados obtidos ao longo deste trabalho de pesquisa indicam que os picos de aceleração calculados para períodos de recorrência de 10 anos e 1 ano, respectivamente, superam os limites recomendados propostos pela NBR 6123 e ISO 10137.
\end{abstract}

Palavras-chave: edifícios, cargas de vento, conforto humano, dinâmica estrutural.

How to cite: A. Barile, L. S. Bastos, and J. G. Santos da Silva, "Human comfort assessment of buildings subjected to nondeterministic wind dynamic loadings", Rev. IBRACON Estrut. Mater., vol. 13, no. 4, e13402, 2020, https://doi.org/10.1590/S1983-41952020000400002

\section{INTRODUCTION}

Currently the construction of tall and slender buildings to meet the demand of population growth and the reduction of free spaces in urban areas has resulted in relevant structural problems related to excessive vibrations and human discomfort caused by the dynamic characteristics of the wind. Because of that, it became imperative to study the 
interaction between wind and tall buildings, in order to improve structural designs avoiding possible future service limit state problems (Barile [1], Bashor [2], Ferrareto [3], Jiurong [4], and Rist [5]).

Although vibrations caused by the wind in most current design situations do not present risks related to the structural collapse, this kind of dynamic action can cause human discomfort. According to occupant surveys and motion simulators, it is well known that people can develop the sensation of tiredness, low motivation, distraction from work activities and low mood, when subject to wind-induced vibrations (Barile [1], Burton [6], Goto [7],Hansen [8], and Lamb [9], [10]).

Generally, design standards consider the wind effect as static loads, calculated from the average speed without considering the components of the fluctuant part that can induce vibrations on the structural system leading to human discomfort. A more realistic analysis can be carried out considering the dynamic characteristics of the wind (Barile [1], Férnandez [11], Liu [12], [13], and Shinozuka [14]). This way, the spectral representation method can be used based on wind series generated with the fluctuant part of the wind determined as a sum of a finite number of harmonics with randomly generated phase angles. This methodology uses a power spectrum and a coherence function to calculate the amplitude of each harmonic and maintaining resemblance to the natural wind (Franco [15] and Shinozuka [14], [16]). Thus, the wind series can be used to simulate the wind dynamic loadings and a reliable human comfort assessment can be verified based on the accelerations values (Bastos [17], Chávez [18], Oliveira [19], Santos [20] and Steffen [21]).

Thus, in this investigation an analysis methodology was developed (Barile [1]), based on the work of Shinozuka et al. [14], [16], aiming to generate nondeterministic dynamic wind loads considering the power spectrum of Kaimal and the coherence function of Davenport. Having in mind to test the developed analysis methodology, a finite element model was created based on a real and existing design of a thirty-storey reinforced concrete building, with total height of $90 \mathrm{~m}$, store height equal to $3 \mathrm{~m}$ and rectangular dimensions of $21.50 \mathrm{~m}$ by $17.30 \mathrm{~m}$ [22]. Finally, the accelerations at the top of the building were calculated and the human comfort was verified. The results obtained along this investigation indicate that the peak accelerations values calculated for periods of recurrence equal to 10 years and 1 year, respectively, overpass the recommended limits proposed by the Brazilian Standard NBR 6123 [23] and also ISO 10137 Standard [24].

\section{NONDETERMINISTIC WIND MODEL}

The nondeterministic wind load was developed based on the methodology proposed by Shinozuka et al. [14], [16]; where the fluctuant wind parcel is generated from the sum of a finite number of overlapping harmonics with random phase angles, see Equation 2. The amplitude of each harmonic is obtained through the spectral power density for the wind and the spatial correlation between the wind velocities at distant points horizontally and vertically. This way, the development of the present analysis methodology has considered the power spectral density of Kaimal, see Equation 4 and the Davenport's spatial correlation, see Equation 5.

In this investigation, it was assumed that wind velocity can be divided into a static part and a turbulent part, according to Equation 1, where $V_{m}$ is the average wind velocity in $\mathrm{m} / \mathrm{s}$ and $\mathrm{v}_{\mathrm{f}}$ is the turbulent part in $\mathrm{m} / \mathrm{s}$. The static part is usually obtained using the mean based on an interval of 10 minutes to 1 hour.

$v(t)=V_{m}+v_{f}(t)$

The turbulent part was obtained based on the "Spectral Representation Method" (Shinozuka et al. [14], [16]). This method consists of generating wind series as a sum of a finite number of superimposed harmonics with random phase angles where the amplitude are calculated using a function that describes a power spectrum and a coherence function for spatial correlation between different points of the investigated structure, see Equation 2.

$$
v_{j}(t)=\sum_{m=l k=l}^{N_{p}} \sum_{N_{\omega}}\left|H_{j m}\left(\omega_{k}\right)\right| \sqrt{\Delta_{\omega}} \cos \left(\omega t+\phi_{k}\right), j=1,2,3 \ldots N_{p}
$$

With reference to Equation 2, $N_{p}$ is the number of points of the structure used to apply the wind load, $N_{\omega}$ is the number of frequencies used to represent the spectrum, $\Delta_{\omega}$ is the frequency increment, $\omega$ is the frequency in $\mathrm{rad} / \mathrm{s}, \phi$ is a random phase angles evenly distributed in the interval $(0-2 \pi)$. In Equation 2 the $\mathrm{H}$ matrix represents the lower part of the cross-spectral density matrix $S(\omega)\left[S(\omega)=H(\omega)^{*} H^{\mathrm{T}}(\omega)\right]$. On the other hand, in Equation 3, S represents the spectral density and $\gamma$ is the coherence function.

$$
S_{j k}(\omega)=\sqrt{S_{j}(\omega) S_{k}(\omega) \gamma_{j k}(\omega)}, j, k=1,2,3, \ldots, N_{p}, j \neq k
$$


In this research work, the mathematical equation proposed by Kaimal was selected to model the power spectral density of the turbulent part of wind longitudinal velocity at different heights of the building, according to Equation 4.

$$
S(\omega)=\frac{2 \pi u^{* 2}}{\omega} \frac{200 n}{(1+50 n)^{5 / 3}} ; n=\frac{\omega z}{2 \pi V_{m}(z)}
$$

With reference to Equation 4, $\mathrm{z}$ is the height, in meters; $\mathrm{f}$ is the frequency, in $\mathrm{Hz}$; $\mathrm{u}^{*}$ is the shear rate of the fluid, in $\mathrm{m} / \mathrm{s}$; and $\mathrm{V}_{\mathrm{m}}(\mathrm{z})$ is the average wind velocity at height $\mathrm{z}$, in $\mathrm{m} / \mathrm{s}$. The coherence function proposed by Davenport was selected to correlate the floating part of the wind at two different points in the space in the coordinates, $\left(\mathrm{z}_{1}, \mathrm{y}_{1}\right)$ and $\left(\mathrm{z}_{2}, \mathrm{y}_{2}\right)$, according to Equation 5.

$$
\operatorname{Coh}\left(r, n_{k}\right)=e^{-f}, f=\frac{n_{k} \sqrt{C_{z}{ }^{2} \Delta_{z}{ }^{2}+C_{y}{ }^{2} \Delta_{y}{ }^{2}}}{\frac{1}{2}\left(V_{m}\left(z_{l}\right)+V_{m}\left(z_{2}\right)\right)}
$$

According to Equation $5, \mathrm{n}_{\mathrm{k}}$ is the frequency in $\mathrm{Hz}, \mathrm{V}\left(\mathrm{z}_{1}\right)$ and $\mathrm{V}\left(\mathrm{z}_{2}\right)$ are the average wind velocities for heights $\mathrm{z}_{1}$ and $\mathrm{z}_{2}$ respectively, in $\mathrm{m} / \mathrm{s} ; \Delta_{\mathrm{z}}$ and $\Delta_{\mathrm{y}}$ are, respectively, the differences between $\mathrm{z}_{1}$ and $\mathrm{z}_{2}$ and between $\mathrm{y}_{1}$ and $\mathrm{y}_{2}$, and $\mathrm{C}_{\mathrm{y}}$ and $\mathrm{C}_{\mathrm{z}}$ are constants which can be used with the value of 10 and 7, respectively. The wind load for each building section (nodes in the FEM), considered in this analysis is obtained using the equation suggested by the Brazilian standard, see Equation 6 .

$$
F_{j}(t)=0.613 v_{j}^{2} C_{a j} A_{e f j}, 1,2,3, \ldots, N_{p}
$$

In Equation 6, v represents the calculated velocity for the building structural section (node in the FEM), using the developed analysis, see Equations $15 ; \mathrm{C}_{\mathrm{a}}$ is a coefficient determined by the design standard NBR 6123 [23] and $\mathrm{A}_{\mathrm{ef}}$ is the effective area, considered for the node in the building FEM.

It is important to emphasize that the time increment for the resulting signal must be less than twice the maximum frequency adopted to avoid the aliasing phenomenon according to the sampling theorem. Thus, the wind dynamic force applied to the structure is obtained through Equation 6.

Considering the nondeterministic characteristics of the natural wind, the final structural response is obtained through the Monte Carlo Method, where a finite number of analyses are required aiming to obtain the structural response that meets the probabilistic criterion, defined by the structural engineer, based on a statistical analysis. The number of analyses depends on the convergence criterion to obtain the structural response.

In sequence, the power spectrum and the spatial correlation are shown in Figures 1 and 2 for the generated wind velocity signal with duration of 600 seconds, based on the developed analysis methodology. Based on the results presented in Figures 1 and 2, it is possible to see the similarity with the functions used by Kaimal and Davenport.

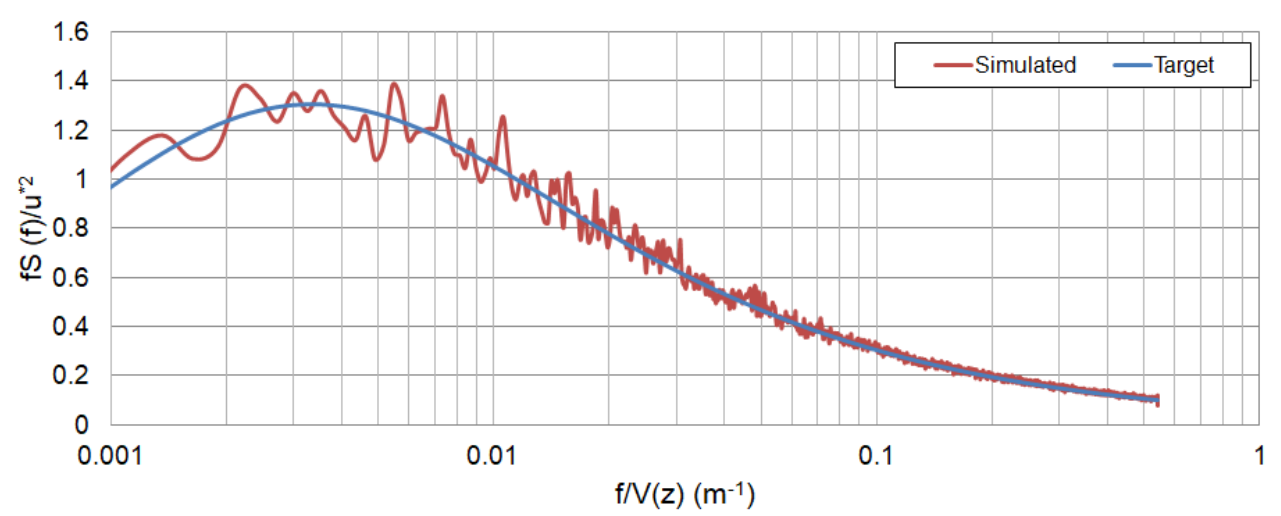

Figure 1. Typical power spectral density of the wind velocity generated for a given position of the structure. 


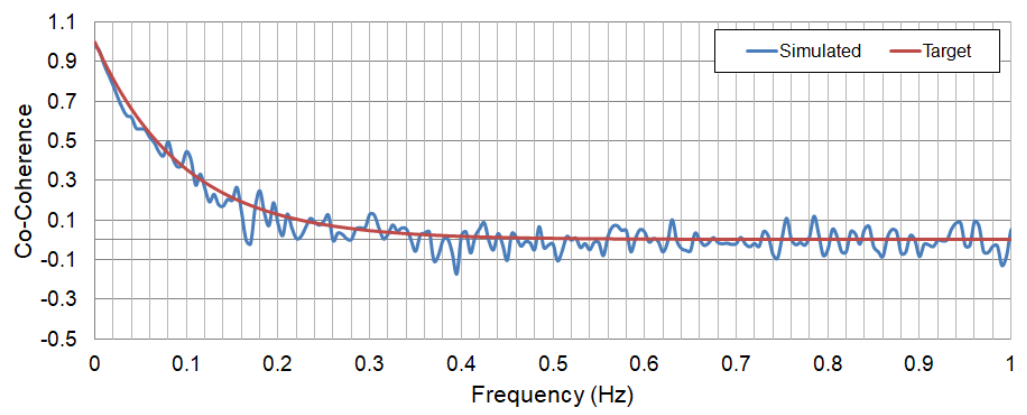

Figure 2. Typical spatial correlation between different points of the structure indicated by the coherence function.

Examples of wind velocities can be seen in Figures 3 and 4, considering three different positions of the structure. It is possible to see that for near, vertical or horizontal distances, the signals present similar characteristics as studied by data obtained from the natural wind and described by the Davenport's correlation function.

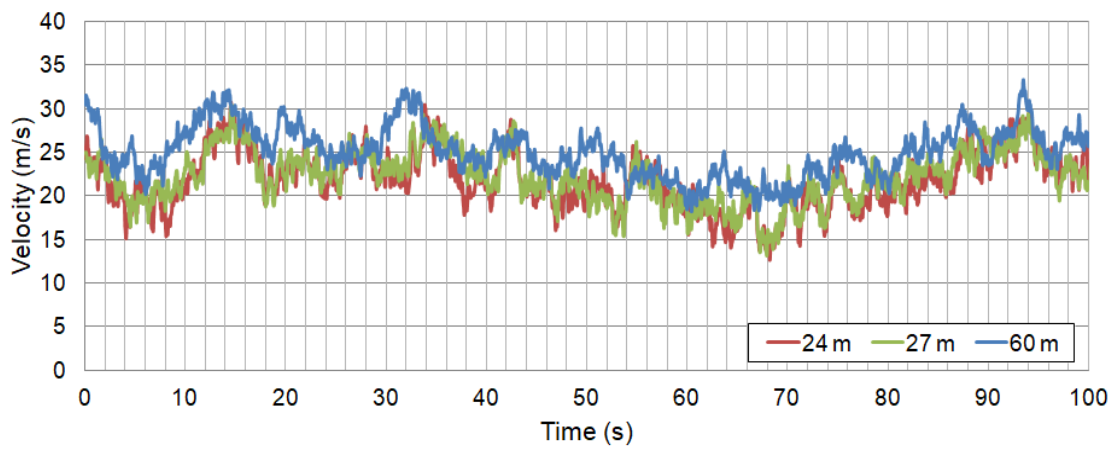

Figure 3. Typical wind speeds for heights of $24 \mathrm{~m}, 27 \mathrm{~m}$ and $60 \mathrm{~m}$ for the same horizontal alignment.

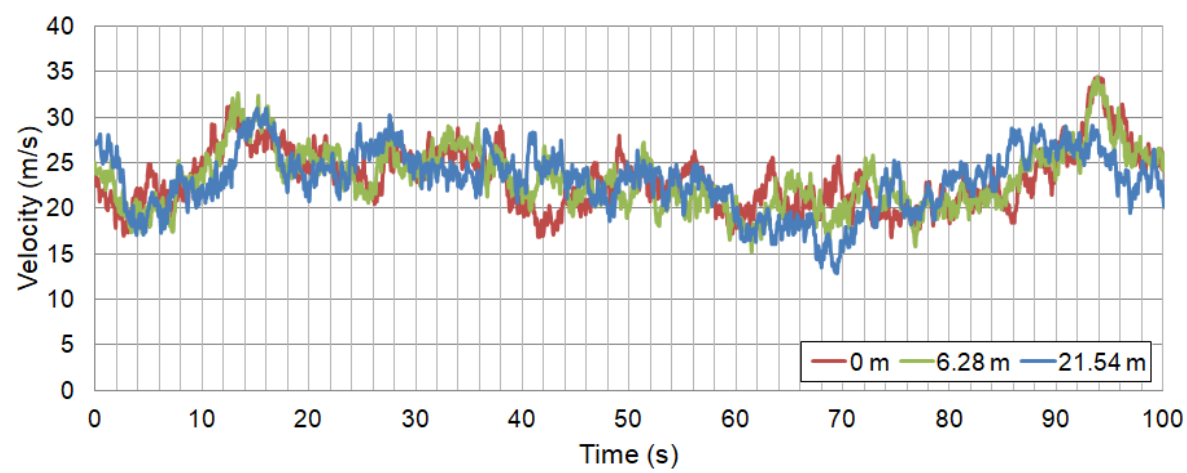

Figure 4. Typical wind speeds for horizontal position of $0,6.28 \mathrm{~m}$ and $21.54 \mathrm{~m}$ for the same vertical alignment of the building.

\section{INVESTIGATED STRUCTURAL MODEL}

The investigated building in this research has plant dimensions of $21.50 \mathrm{~m}$ by $17.30 \mathrm{~m}$, presents 30 floors, with a height of $3.0 \mathrm{~m}$, total height $90 \mathrm{~m}$, as shown in Figure 5. The structure, made of reinforced concrete, consists of massive concrete slabs with a thickness equal to $18 \mathrm{~cm}$, girders with sections $30 \times 60 \mathrm{~cm}$ and columns with sections $30 \times 80 \mathrm{~cm}$ in their majority. The structural model does not have girders dividing the internal spans of the slabs, but even so, the periphery beams together with the columns can compose structural frames that contributes to the bracing of the building (Bastos [22]), as illustrated in Figures 5 and 6. 


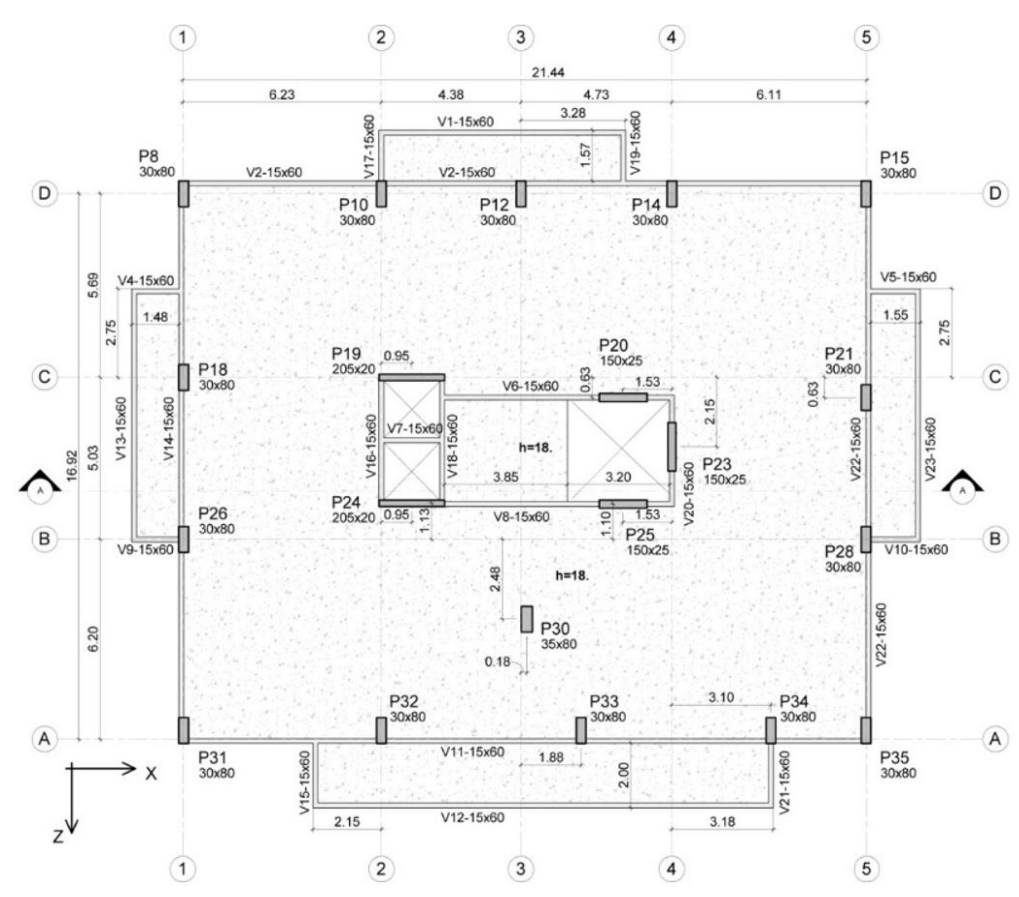

a) Structural floor plant

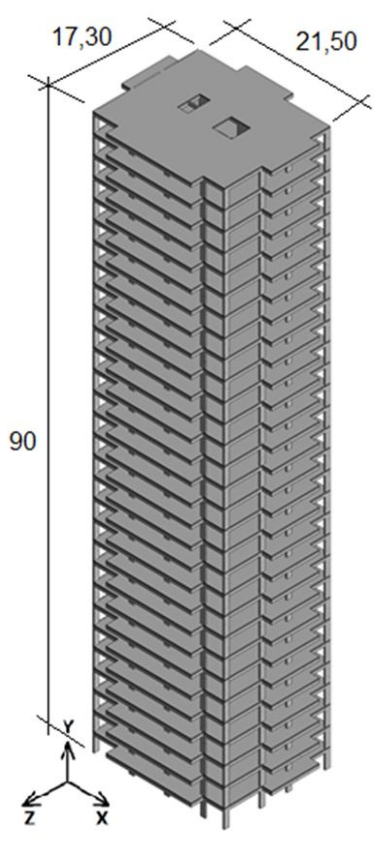

b) 3D model perspective

Figure 5. Investigated structural model.

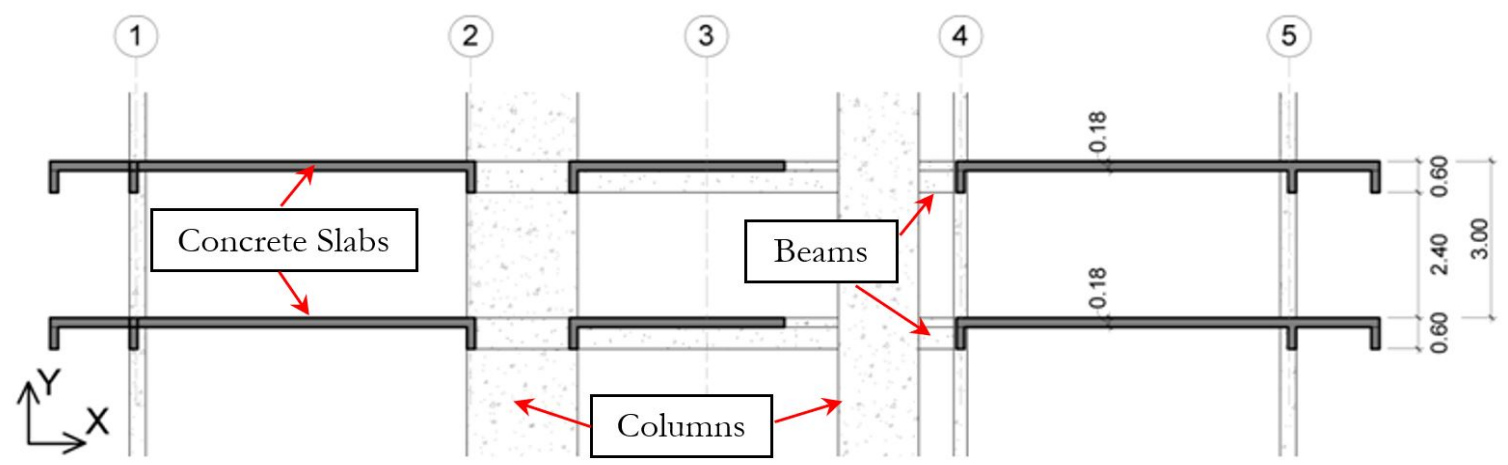

Figure 6. Detail of the concrete slabs thickness and height floor-to-floor.

The structural concrete used has compression strength $\left(\mathrm{f}_{\mathrm{ck}}\right)$ of $45 \mathrm{MPa}$, Young's modulus $\left(\mathrm{E}_{\mathrm{cs}}\right)$ of $34 \mathrm{GPa}$, a Poisson's coefficient (v) equal to 0.2 and density $\left(\gamma_{c}\right)$ of $25 \mathrm{kN} / \mathrm{m}^{3}$. Usual design and permanent loads $\left(1.0 \mathrm{kN} / \mathrm{m}^{2}\right)$ and accidental $(1.5 \mathrm{kN} / \mathrm{m} 2)$ loads were added to the slabs of all floors. The total weight of masonry was distributed evenly over the slabs $\left(2.8 \mathrm{kN} / \mathrm{m}^{2}\right)$.

\section{FINITE ELEMENT MODELLING OF THE BUILDING}

The proposed numerical model, developed for the reinforced concrete building dynamic analysis, adopted the usual mesh refinement techniques present in finite element method simulations implemented in the ANSYS program (ANSYS, 2009). In this model, the reinforced concrete girders and columns were represented by three-dimensional BEAM44 finite elements, where the effects of bending and torsion are considered. The uniaxial finite element BEAM44 is composed of two nodes and each node with six degrees of freedom (translations and rotations in $\mathrm{X}, \mathrm{Y}$ and $\mathrm{Z}$ directions). The advantage of this element is the possibility of allowing its nodes to be spaced from the centroid axis of the beams, since the slab and the beam are not positioned on the same axis. This eccentricity is considered in the 
modelling, because affects the values of the building natural frequencies. On the other hand, the concrete slabs were represented based the SHELL63 finite elements. Four nodes and each node with six degrees of freedom (translations and rotations in $\mathrm{X}, \mathrm{Y}$ and $\mathrm{Z}$ directions) define the shell finite element SHELL63.

The developed numerical model presents an appropriate degree of refinement, aiming to a good representation of the dynamic structural behaviour of the building, see Figure 7. Table 1 presents the characteristics of the numerical model (nodes, elements and degrees of freedom). The support conditions were assumed as a pin-joint, considering that all the building supports were restricted to vertical and horizontal translational and free for rotational displacements.

Table 1 Characteristics of the developed building finite element model.

\begin{tabular}{cc}
\hline & FEM of the Building \\
\hline Number of Nodes & 232552 \\
\hline Number of Elements & 245880 \\
\hline Number of Degrees of Freedoms (DOF) & 1395246 \\
\hline
\end{tabular}

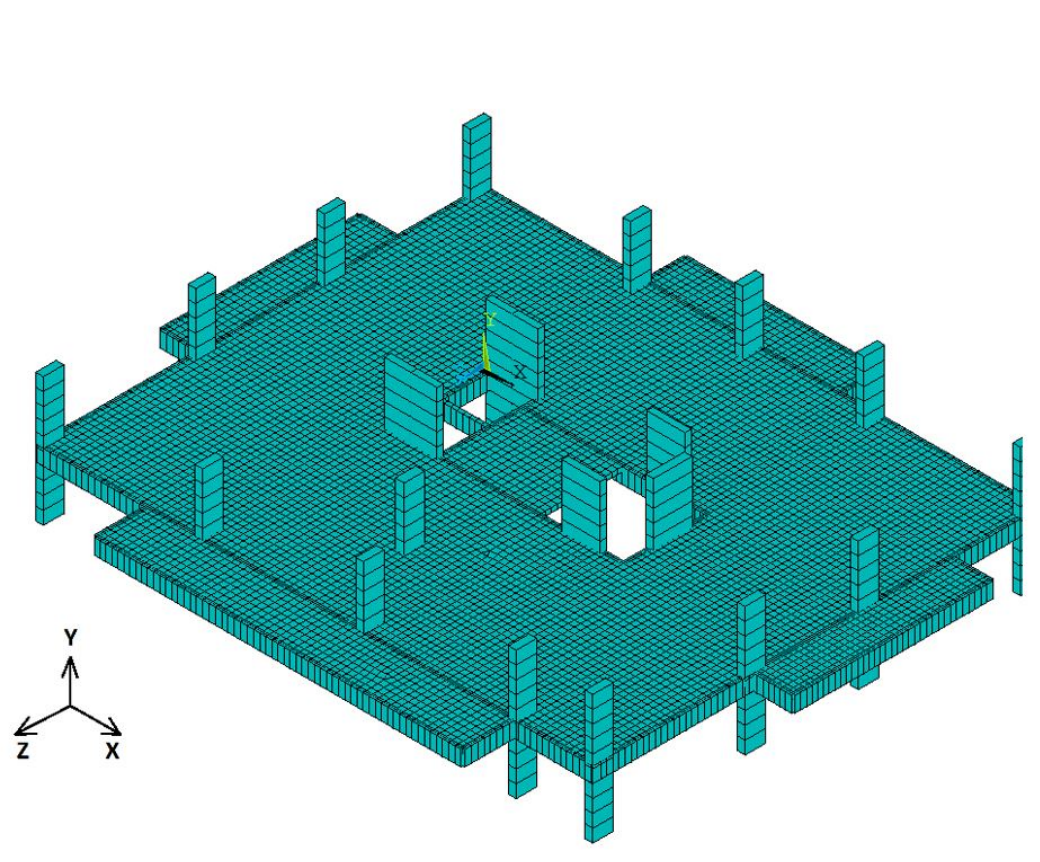

a) FEM: 3D view of typical floor plant

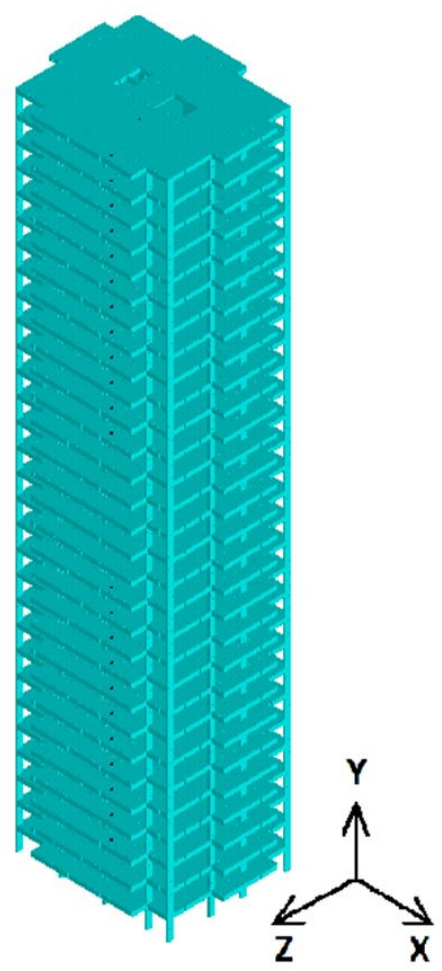

b) FEM: perspective

Figure 7. Finite element model of the investigated building.

\section{NATURAL FREQUENCIES AND VIBRATION MODES OF THE BUILDING}

The natural frequencies (eigenvalues) and the vibration modes (eigenvectors) of the structure were obtained based on numerical methods of extraction (modal analysis), through a free vibration analysis and using the ANSYS (2009) computational program. The first four vibration modes of the analysed building are shown in Figure 8. The fundamental frequency of $0.25 \mathrm{~Hz}\left(\mathrm{f}_{01}=0.25 \mathrm{~Hz}\right)$, obtained through the modal analysis shows the need for dynamic analysis of the building since, as can be seen from the power spectrum presented in Figure 1, the largest transfer of wind energy is concentrated in the region of low frequencies. In order to study the situation that will cause the higher displacements and accelerations, the Z-direction (see Figure 8) was chosen to apply the non-deterministic wind loadings on the structure, since the lowest structural frequency corresponds to the bending around the $\mathrm{X}$ axis (see Figure 8). 


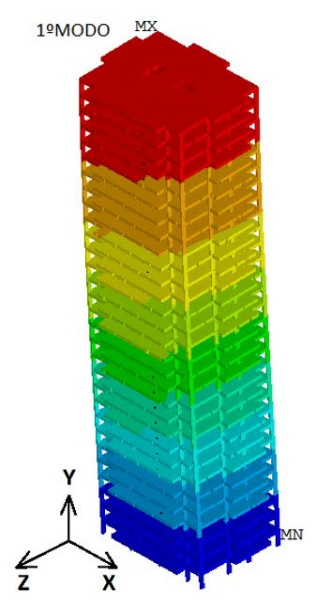

1st Vibration mode $\left(\mathrm{f}_{01}=0.25 \mathrm{~Hz}\right)$

Bending around $\mathrm{X}$-axis

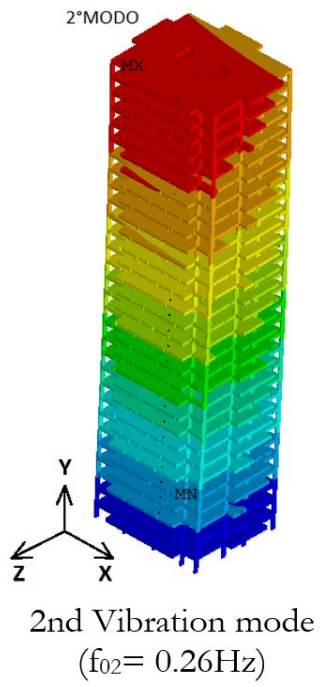

Bending around $Z$-axis

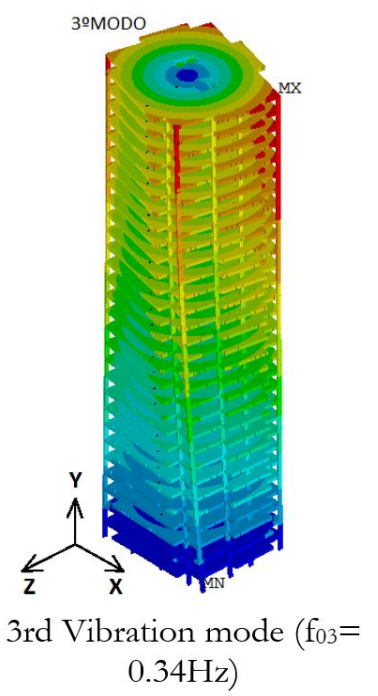

Torsion around $\mathrm{Y}$-axis

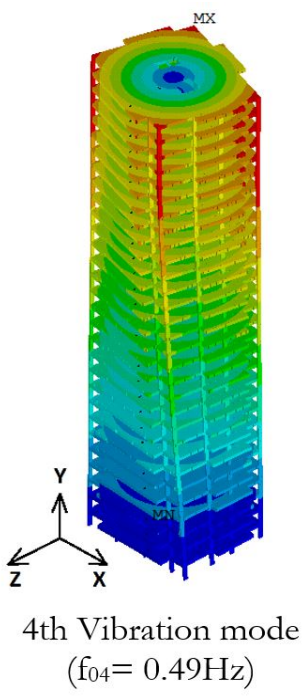

Torsion around $\mathrm{Y}$-axis

Figure 8. Vibration modes of the investigated building.

\section{NONDETERMINISTIC DYNAMIC ANALYSIS}

Based on the use of the finite element program ANSYS (2009), forced vibration dynamic analyses were performed on the investigated structural model. In addition to the usual vertical design loads, the nondeterministic wind action was applied on the largest façade of the building [Z-direction, see Figure 7)]. The basic wind speed was determined considering, initially, a time of recurrence of 10 years (NBR 6123 [23]), and after that a period of recurrence equal to 1 year was considered (ISO 10137 [24]). The results of the dynamic analyses were obtained at the top of the building $(\mathrm{h}=90 \mathrm{~m})$, when the maximum horizontal translational displacements were analysed, and at the floor of the last building store $(\mathrm{h}=87 \mathrm{~m})$, when the maximum accelerations were investigated.

Since the wind dynamic actions considered in this research work have nondeterministic characteristics, it is not possible to predict the response of the structure at a certain instant of time. Thus, a reliable response can be achieved through appropriate statistical treatment, based on the use of Equation 7. This way, considering that the dynamic structural response presents a normal distribution, and based on the calculation of the mean $(\mathrm{m})$ and also the standard deviation $(\sigma)$, it is possible to obtain the characteristic value $\left(\mathrm{U}_{z 95 \%}\right)$ that corresponds to a reliability of $95 \%$, meaning that only $5 \%$ of the sampled values will exceed this value [9].

$U_{z 95 \%}=1.65 \sigma+m$

In this research work, aiming to attend the period of recurrence of the design standards traditionally used for the human comfort assessment (NBR 6123 [23], ISO 10137 [24]), two wind loading scenarios were considered. The first one with a period of recurrence equal to 10 years, adopted by NBR 6123 [23], and the second considering 1 year of recurrence, according to ISO 10137 [24]. For each scenario, 30 nondeterministic wind series were generated to investigate the dynamic structural behaviour of the analysed building.

The parameters used to generate the wind series are shown in Table 2 Parameters used to generate the nondeterministic wind series. Based on the NBR 6123 [23] recommendations, the basic wind velocity represents the wind for the city of Rio de Janeiro that occurs at least one time in 50 years, with duration of 3 seconds, and the category II is related to open lands in level with few isolated obstacles. The topographic factor $\mathrm{S}_{1}$ equal to 1 corresponds to a situation of flat terrain that is weakly uneven. The category is used to determine the parameters for the calculation of the factor $\mathrm{S}_{2}$ that indicates the variation of the velocity according to the height and roughness of the terrain. The probabilistic factor $\mathrm{S}_{3}$, was obtained in order to satisfy the period of recurrence of 10 years proposed by NBR 6123 [23], and also considering a period of recurrence equal to 1 year, according to ISO 10137 [24]. In both situations, a probability of occurrence equal to $63 \%$ is considered. The time duration of 10 minutes (600 seconds) is usually adopted to study wind effects in structures. 
Table 2 Parameters used to generate the nondeterministic wind series.

\begin{tabular}{cc}
\hline Design Parameters & Recommended Values \\
\hline Wind Basic Velocity $\left(\mathrm{V}_{0}\right)$ & $35 \mathrm{~m} / \mathrm{s}$ \\
\hline Terrain Category & $\mathrm{II}$ \\
\hline Topographic Factor $\left(\mathrm{S}_{1}\right)$ & 1 \\
\hline Parameters for Roughness Factor $\left(\mathrm{S}_{2}\right)$ & $\mathrm{b}=1$ and $\mathrm{p}=0.15$ \\
\hline Probability Factor $\left(\mathrm{S}_{3}\right)$ & $0.76(10$ years $)$ and $0.53(1$ year $)$ \\
\hline Time Duration & 600 seconds \\
\hline Time Increment & 0.03 seconds \\
\hline
\end{tabular}

Figures 9 and 10 present a typical example of the wind dynamic force in the time and frequency domain, respectively. It is relevant to observe through the generated wind nondeterministic characteristic, the range of excitation frequencies that represent the harmonics of the signal. It must be emphasized that the fundamental frequency, related to the first vibration mode of the structure (bending around X-axis, see Figure 8), responsible for the higher energy transfer peak of the system in the dynamic analysis was represented in the signal.

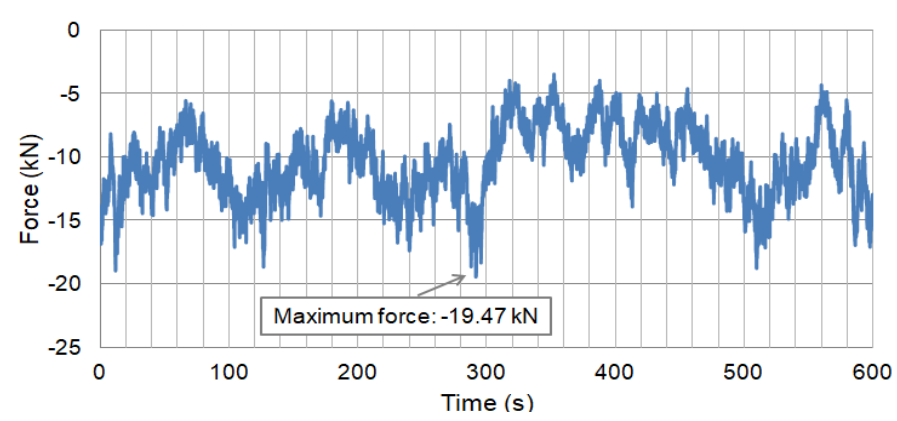

Figure 9. Typical example of nondeterministic wind loading in the time domain (period of recurrence of 10 years).

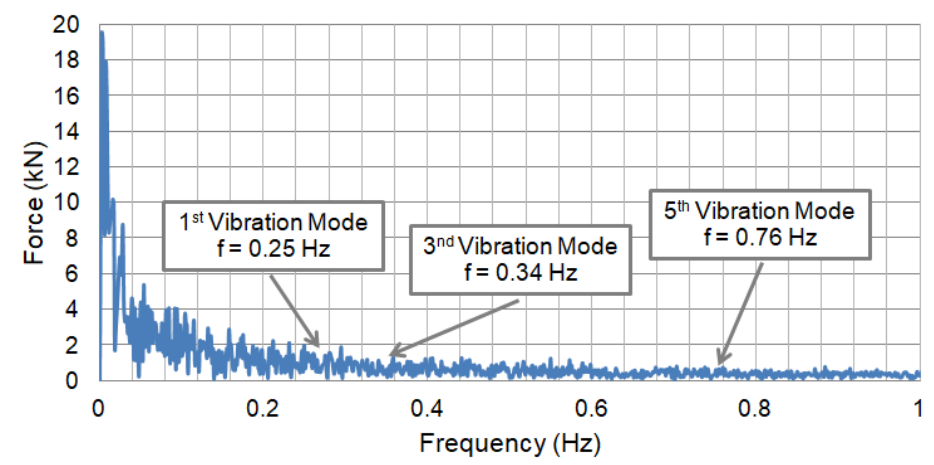

Figure 10. Typical example of nondeterministic wind loading in the frequency domain (period of recurrence of 10 years).

The dynamic structural behaviour of the building over time, when the structure is subjected to non-deterministic wind loadings, can be observed with greater clarity in the next Figures 11 to 13. Figure 11 shows a typical example of the translational horizontal displacements at the top of the structure, over 10 minutes, where it is possible to verify that the maximum horizontal translational displacement value is below the recommended limit proposed by the Brazilian Standard NBR 6118 [25]. In sequence, a typical example of the acceleration result can be seen in Figure 12, attempting to the fact that the maximum acceleration value exceeded the limit proposed by NBR 6123 [23], which would lead to the modification of the structural design, aiming to attend human comfort. After that, Figure 13 illustrates the accelerations in frequency domain, obtained through the Fast Fourier Transform (FFT). It is possible to verify that the main energy transfer peak (greater amplitude of displacement) is associated to resonance related to the building fundamental frequency (first natural frequency: $\mathrm{f}_{01}=0.25 \mathrm{~Hz}$ ), corresponding to the first vibration mode (bending around the X-axis, see Figure 8). 


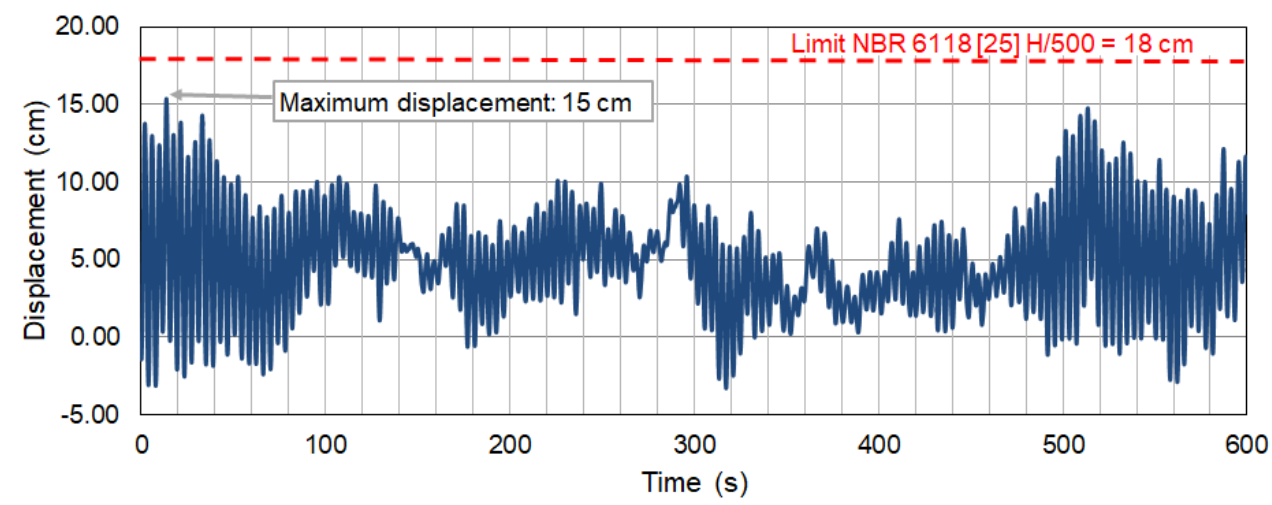

Figure 11. Example of translational horizontal displacement result at 90 meters high (period of recurrence of 10 years).

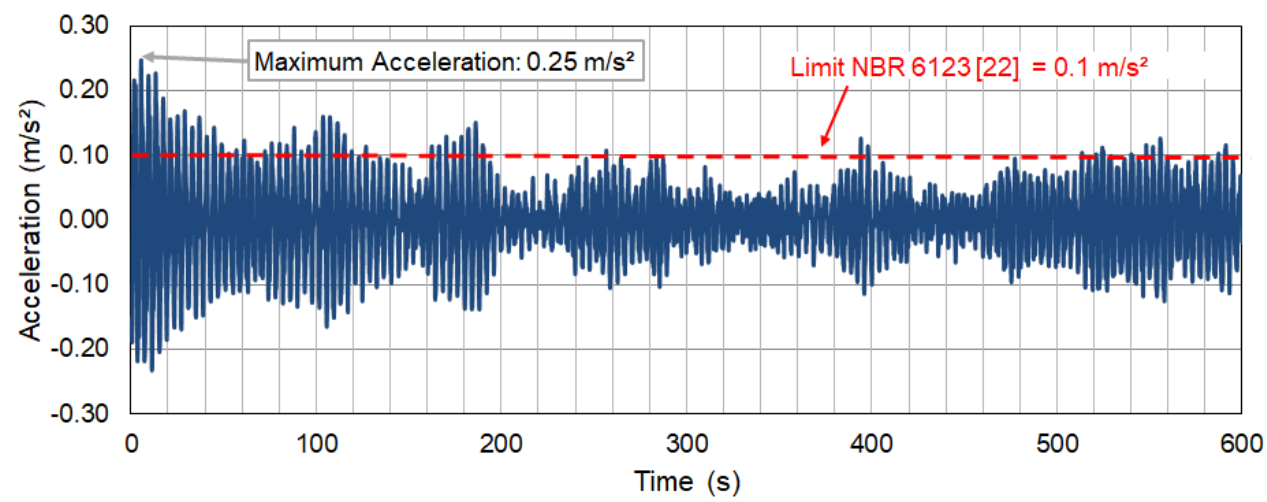

Figure 12. Example of acceleration result at 87 meters high (period of recurrence of 10 years).

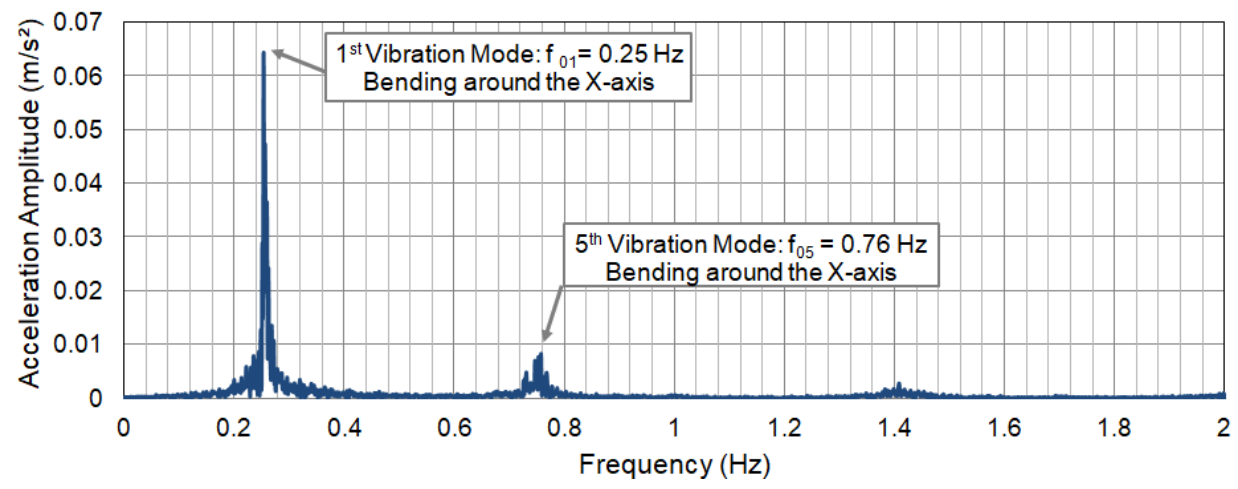

Figure 13. Example of acceleration at 87 meters high in the frequency domain (period of recurrence of 10 years).

As far as the convergence of the numerical results is concerned, Figure 14 illustrates the characteristic horizontal translational displacements $\left(\mathrm{U}_{z 95 \%}\right)$ at the top of the reinforced concrete building (see Figures 5 and 7 ), calculated gradually over the results of each series, pointing out to the importance of applying an adequate number of nondeterministic wind series in order to obtain a consistent result.

In sequence of the investigation, having in mind a quantitative analysis of the results, Table 3 presents the maximum translational horizontal displacements and accelerations, respectively, calculated at the top of the building $(\mathrm{h}=90 \mathrm{~m})$ and at the last floor $(\mathrm{h}=87 \mathrm{~m})$, see Figures 5 and 7, considering each nondeterministic wind series applied on the investigated building, and also the mean values $(\mu)$, standard deviation $(\sigma)$ and characteristics values calculated based on the generated 30 series for each investigated scenario [see Equations 1-6]. 


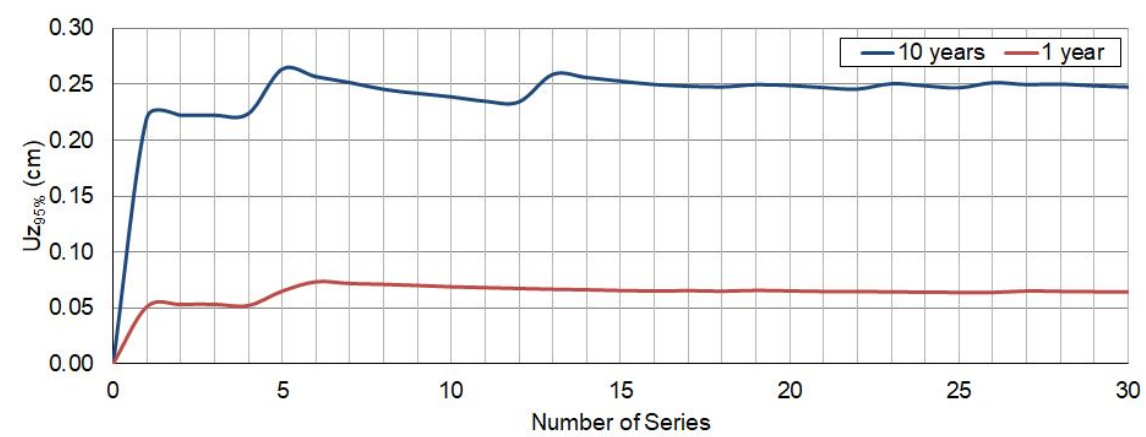

Figure 14. Convergence of the characteristic displacements values considering a period of recurrence equal to 10 years and 1 year.

Table 3 Dynamic structural response of the investigated building: maximum displacements and peak accelerations values.

\begin{tabular}{|c|c|c|c|c|}
\hline \multirow{2}{*}{$\begin{array}{l}\text { Nondeterministic } \\
\text { Loading Series }\end{array}$} & \multicolumn{2}{|c|}{ Time of recurrence: 10 years } & \multicolumn{2}{|c|}{ Time of recurrence: 1 year } \\
\hline & $\begin{array}{c}\text { Displacements } \\
U_{\mathrm{Z}}(\mathrm{cm})\end{array}$ & $\begin{array}{c}\text { Accelerations } \\
a_{p}\left(\mathbf{m} / \mathbf{s}^{2}\right)\end{array}$ & $\begin{array}{c}\text { Displacements } \\
U_{\mathrm{Z}}(\mathrm{cm})\end{array}$ & $\begin{array}{c}\text { Accelerations } \\
a_{p}\left(\mathbf{m} / \mathbf{s}^{2}\right)\end{array}$ \\
\hline 1 & 12.13 & 0.22 & 5.11 & 0.07 \\
\hline 2 & 13.93 & 0.22 & 4.83 & 0.08 \\
\hline 3 & 13.44 & 0.21 & 4.51 & 0.08 \\
\hline 4 & 14.99 & 0.22 & 4.61 & 0.07 \\
\hline 5 & 10.10 & 0.13 & 6.56 & 0.10 \\
\hline 6 & 12.03 & 0.16 & 7.20 & 0.10 \\
\hline 7 & 11.25 & 0.15 & 5.52 & 0.09 \\
\hline 8 & 11.71 & 0.16 & 5.80 & 0.09 \\
\hline 9 & 13.42 & 0.19 & 4.37 & 0.07 \\
\hline 10 & 13.13 & 0.14 & 4.77 & 0.09 \\
\hline 11 & 13.83 & 0.16 & 4.10 & 0.06 \\
\hline 12 & 13.73 & 0.20 & 5.21 & 0.08 \\
\hline 13 & 20.44 & 0.29 & 4.28 & 0.07 \\
\hline 14 & 11.78 & 0.19 & 5.31 & 0.08 \\
\hline 15 & 12.37 & 0.17 & 4.41 & 0.07 \\
\hline 16 & 11.99 & 0.16 & 3.96 & 0.06 \\
\hline 17 & 13.81 & 0.19 & 5.83 & 0.09 \\
\hline 18 & 13.84 & 0.20 & 4.90 & 0.07 \\
\hline 19 & 12.67 & 0.22 & 6.14 & 0.09 \\
\hline 20 & 11.32 & 0.13 & 4.62 & 0.06 \\
\hline 21 & 14.02 & 0.18 & 4.56 & 0.08 \\
\hline 22 & 14.02 & 0.14 & 5.56 & 0.09 \\
\hline 23 & 15.37 & 0.24 & 5.14 & 0.07 \\
\hline 24 & 13.01 & 0.15 & 5.05 & 0.08 \\
\hline 25 & 12.34 & 0.15 & 5.25 & 0.08 \\
\hline 26 & 13.43 & 0.25 & 5.59 & 0.07 \\
\hline 27 & 10.38 & 0.15 & 6.62 & 0.11 \\
\hline 28 & 12.77 & 0.21 & 4.84 & 0.07 \\
\hline 29 & 11.64 & 0.17 & 5.00 & 0.07 \\
\hline 30 & 12.93 & 0.19 & 5.36 & 0.08 \\
\hline Mean (m) & 13.06 & 0.18 & 5.17 & 0.08 \\
\hline Standard Deviation $(\sigma)$ & 1.80 & 0.04 & 0.74 & 0.01 \\
\hline $\mathbf{U}_{\mathbf{z 9 5} \%}$ & 16.04 & 0.25 & 6.39 & 0.10 \\
\hline
\end{tabular}

$\mathrm{U}_{\lim }=18 \mathrm{~cm}$ (NBR 6118 [25]); $\mathrm{a}_{\lim }=0.10 \mathrm{~m} / \mathrm{s}^{2}$ (NBR 6123 [23]); $\mathrm{a}_{\lim }=0.075 \mathrm{~m} / \mathrm{s}^{2}($ ISO 10137 [24])

The human comfort criteria can be verified using the peak accelerations values of the nondeterministic signals, see Table 3 . The results show peak accelerations (mean maximum values), equal to $0.25 \mathrm{~m} / \mathrm{s}^{2}$ (time of recurrence: 10 years; NBR 6123 [23]), and $0.10 \mathrm{~m} / \mathrm{s}^{2}$ (time of recurrence: 1 year; ISO 10137 [24]), respectively, see Table 3. It must be emphasized that these values overpass the recommended limits proposed by the Brazilian Standard NBR 6123 [23] $\left(\mathrm{a}_{\mathrm{p}}=0.25 \mathrm{~m} / \mathrm{s}^{2}>\mathrm{a}_{\mathrm{lim}}=0.10 \mathrm{~m} / \mathrm{s}^{2}\right)$, and ISO 10137 [24] Standard $\left(a_{\mathrm{p}}=0.10 \mathrm{~m} / \mathrm{s}^{2}>\mathrm{a}_{\mathrm{lim}}=0.075 \mathrm{~m} / \mathrm{s}^{2}\right)$, when the building dynamic structural response was considered. 
In sequence of the analysis, Figure 15 presents the maximum displacements values [top of the building: $\mathrm{h}=90 \mathrm{~m}$, see Figures 5 to 7], obtained for each nondeterministic wind series considering, respectively, a period of recurrence equal to 10 years (NBR 6123 [23]) and 1 year (ISO 10137 [24]). It is possible to verify that most of these displacements attend the limit proposed by the standard NBR 6118 [25].

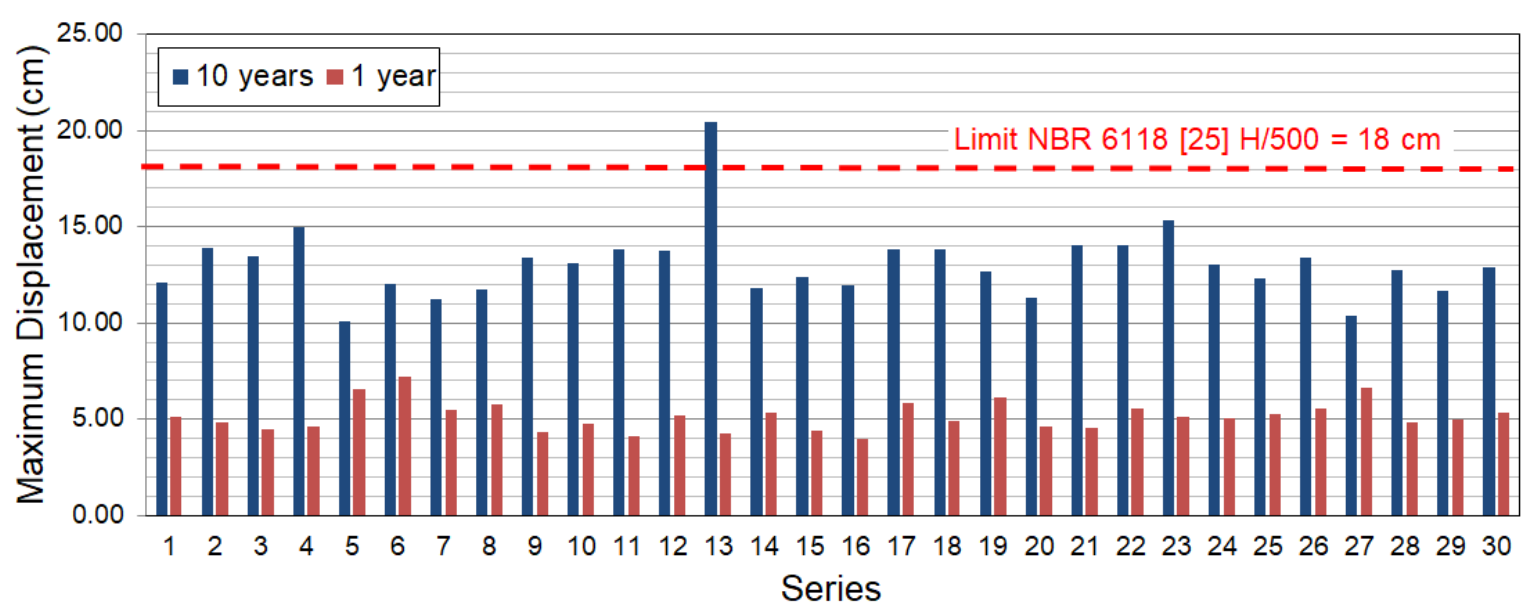

Figure 15. Maximum translational horizontal displacements obtained for each nondeterministic wind series based on a period of recurrence equal to 10 years and 1 year.

Considering the peak accelerations [last floor: $\mathrm{h}=87 \mathrm{~m}$, see Figures 5 to 7], Figure 16 clearly shows that these accelerations values are far above the limit of $0.10 \mathrm{~m} / \mathrm{s}^{2}$ (time of recurrence: 10 years), proposed by NBR 6123 [23]. On the other hand, having in mind the limit of $0.075 \mathrm{~m} / \mathrm{s}^{2}$ (period of recurrence: 1 year), obtained according to ISO 10137 [24], in many situations this recommended limit was also surpassed. This way, it can be concluded, having in mind the investigated building with fundamental frequency of $0.25 \mathrm{~Hz}\left(\mathrm{f}_{01}=0.25 \mathrm{~Hz}\right)$, that most of the peak accelerations violate the recommended limits for human comfort assessment.

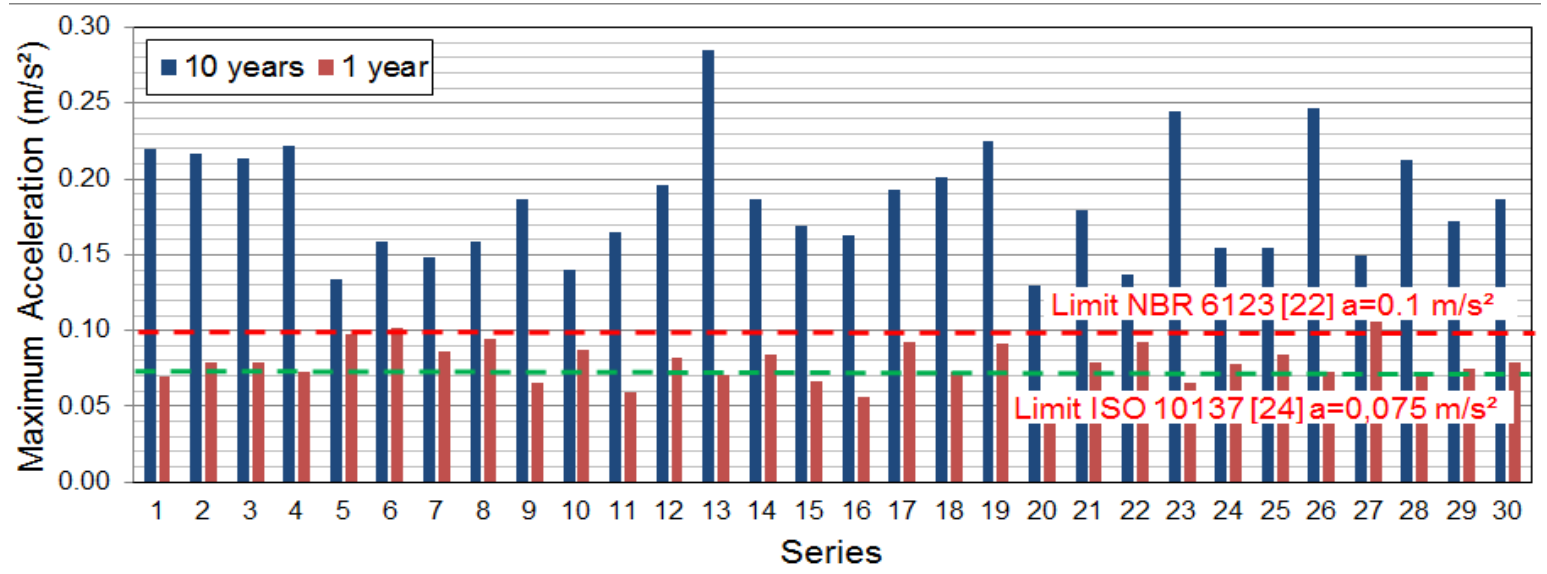

Figure 16. Maximum accelerations values obtained for each nondeterministic wind series considering a period of recurrence of 10 years and 1 year.

\section{CONCLUSIONS}

This investigation presents the results of a forced vibration dynamic analysis carried out based on a three-dimensional finite element model developed to represent a real and existing residential building $(\mathrm{H}=90 \mathrm{~m})$, when subjected to non-deterministic wind loads. The turbulent wind velocity was calculated through the summation of a finite number of superimposed harmonics 
with random phase angles and the amplitude of each harmonic was determined using a power spectral density function. The human comfort assessment of the building was performed, based on comparisons between the peak accelerations and the recommended limits proposed by the Brazilian Standard NBR 6123 [23] and also ISO 10137 Standard [24].

It can be seen that the power spectrum of the wind velocity is in good agreement with the formula proposed by Kaimal, indicating that the developed analysis methodology leads to a velocity signal close to the natural wind velocity. On the other hand, using the wind velocities of two different points on the structure it was possible to obtain the coherence between their velocities indicating a good agreement with the coherence formula proposed by Davenport.

Based on the results of the modal analysis, the value of $0.25 \mathrm{~Hz}\left(\mathrm{f}_{01}=0.25 \mathrm{~Hz}\right)$ was obtained for the fundamental frequency of the structure which, according to the Brazilian design standard NBR 6123 [23], makes the forced vibration analysis necessary.

Displacements and accelerations result values show that although the displacement values are within the limit proposed by the standard NBR 6118 [25], the peak accelerations values surpass the proposed limits of $0.10 \mathrm{~m} / \mathrm{s}^{2}\left(\mathrm{a}_{\mathrm{p}}=0.25 \mathrm{~m} / \mathrm{s}^{2}>\mathrm{a}_{\mathrm{lim}}=0.10 \mathrm{~m} / \mathrm{s}^{2}\right.$; NBR 6123 [23]: period of recurrence of 10 years $)$ and $0.075 \mathrm{~m} / \mathrm{s}^{2}$ $\left(a_{p}=0.10 \mathrm{~m} / \mathrm{s}^{2}>a_{\lim }=0.075 \mathrm{~m} / \mathrm{s}^{2}\right.$; ISO 10137 [24]: period of recurrence of 1 year $)$, emphasizing the relevance of the human comfort assessment of tall buildings.

Finally, the authors would like to emphasize the need to continue the research, based on the evaluation of the soil-structure interaction effect and also the masonry infills influence on the dynamic response of the structural model, aiming to contribute with a more realistic assessment of the dynamic structural behaviour and human comfort evaluation of tall buildings.

\section{ACKNOWLEDGEMENTS}

The authors gratefully acknowledge the financial support for this work provided by the Brazilian Science Foundation's CAPES, CNPq and FAPERJ.

\section{REFERENCES}

[1] A. Barile, "Development of a methodology for nondeterministic dynamic analysis and human comfort assessment of tall buildings," (in Portuguese), M.S. thesis, Civil Eng. Postgraduate Program., State Univ. Rio de Janeiro, Rio de Janeiro, RJ, Brazil, 2019.

[2] R. Bashor, S. Bobby, T. Kijewski-Correa, and A. Kareem, "Full scale performance evaluation of tall buildings under wind," J. Wind Eng. Ind. Aerodyn., vol. 104-106, pp. 88-97, May/July 2012.

[3] J. A. Ferrareto, "Human comfort in tall buildings subjected to wind-induced motion," (in Portuguese), Ph.D. dissertation, Univ. São Paulo, São Paulo, SP, Brazil, 2017.

[4] W. Jiurong, "Field measurements and numerical study of wind effects on tall buildings," Ph.D. dissertation, City Univ. Hong Kong, Hong Kong, China, 2006.

[5] V. C. Rist, "Methodology for preliminary design of high-rise buildings," M.S. thesis, Lund Univ., Lund, Sweden, 2016.

[6] M. Burton, K. C. S. Kwok, and A. Abdelrazaq, "Wind-induced motion of tall buildings: Design for occupant comfort," Int. J. of High-Rise Blgd. vol. 4, no. 1, pp. 1-8, Mar. 2015.

[7] T. Goto, "Studies on wind-induced motion of tall buildings based on occupants reactions," J. Wind Eng. Ind. Aerodyn., vol. 13, pp. 241-252, July 1983.

[8] R. J. Hansen, J. W. Reed, and E. H. Vanmarcke, "Human response to wind-induced motion buildings," J. Struct. Div., vol. 99, pp. 66-74, 1973.

[9] S. M. Lamb, K. C. S. Kwok, and D. Walton, "A longitudinal field study of the effects of wind-induced building motion on occupant wellbeing and work performance," J. Wind Eng. Ind. Aerodyn., vol. 133, pp. 39-51, July 2014.

[10] S. M. Lamb, “The effect of wind-induced tall building motion on occupant comfort, wellbeing and work performance,” Ph.D. dissertation, Univ. Western Sydney, Sydney, Australia, 2013.

[11] I. Fernández and V. E. Parnás, “Elements for numerical simulation of wind time series,” Rev. Ing. Constr., vol. 32, no. 2, pp. 85-92, Aug 2017.

[12] Z. Liu, W. Liu, and Y. Peng, "Random function based spectral representation of stationary and non-stationary stochastic processes," Probab. Eng. Mech., vol. 45, pp. 115-126, July 2016.

[13] J. Chen, F. Kong, and Y. Peng, "A stochastic harmonic function representation for non-stationary stochastic processes," Mech. Sys. Sig. Prcsg., vol. 96, pp. 31-44, November 2017.

[14] M. Shinozuka and C. M. Jan, "Digital simulation of random process and its application," J. Sound Vibrat., vol. 25, no. 1, pp. 111128, Apr 1972. 
[15] M. Franco Direct along-wind dynamic analysis of tall structures (Report, BT/PEF/9303). São Paulo, SP, Brazil: University of São Paulo, 1993.

[16] M. Shinozuka Stochastic Methods In Structural Dynamics. Dordrecht: Springer, 1987.

[17] F. J. D. Bastos, “Aerodynamic behaviour of slender structures: gust effect analysis”, M.S. thesis, Fac. Eng., Porto Univ., Porto, Portugal, 2008.

[18] E. S. Chávez, "Structural analysis of tall building submitted to floating pressures induced by wind action," (In Portuguese), M.S. thesis, Federal Univ. Minas Gerais, Belo Horizonte, MG, Brazil, 2006.

[19] B. D. Oliveira, "Wind effect as dynamic action on tall buildings," (In Portuguese), M.S. thesis, Fac. Eng. Porto Univ., Porto, Portugal, 2015.

[20] V. H. Santos, "Comparison between the Discrete Method NBR 6123 and the Synthetic Wind Method for multi-storey reinforced concrete buildings," (In Portuguese), M.S. thesis, Federal Univ. Paraná, Curitiba, PR, Brazil, 2018.

[21] F. Steffen, "Wind-induced vibrations in high-rise buildings," M.S. thesis, Lund Univ., Lund, Sweden, 2016.

[22] L.S. Bastos, "Estudo do comportamento estrutural e análise de conforto humano de edifícios de concreto armado", (In Portuguese), M.S. thesis, Civil Eng. Postgraduate Program., State Univ. Rio de Janeiro, Rio de Janeiro, RJ, Brazil, 2015.

[23] Associação Brasileira de Normas Técnicas. NBR 6123: Forças devidas ao vento em edificações, 1988.

[24] International Organization for Standardization, Bases for Design of Structures - Serviceability of Buildings and Walkways Against Vibrations, ISO 10137:2007, 2007.

[25] Associação Brasileira de Normas Técnicas. NBR 6118: Projeto de estruturas de concreto - Procedimento, 2014.

Author contributions: Alan Barile: conceptualization, methodology, analysis, writing; Leonardo de Souza Bastos: conceptualization, methodology, analysis; José Guilherme Santos da Silva: conceptualization, methodology, analysis, writing, supervision.

Editors: Mauro de Vasconcellos Real, José Luiz Antunes de Oliveira e Sousa, Guilherme Aris Parsekian. 